\title{
Welcome to ThCVS Reports
}

\author{
Andreas Böning, Editor
}

Thorac Cardiovasc Surg Rep 2012;1:1-2.

The well-established "Thoracic and Cardiovascular Surgeon" now has a little brother: "Thoracic and Cardiovascular Surgeon Reports". It was the ThCVS editors' and publisher's decision to outsource case reports from the ThCVS into an Open Access journal containing case reports only. This "ThCVS Reports" journal has a peer review process very similar to the ThCVS, since the reviewer list remains constant and the new "Instructions for Authors" are similar for Big ThCVS and Small ThCVS Reports.

Online publication speeds up the publication process and refers to the reading practice of the scientific audience avoiding paper prints and doing literature search online. This is valid also for case reports, which still have to be published for several reasons: Case reports are important because they reflect new developments in surgical techniques, show treatment modalities in rare diseases, and remind readers to think outside the usual tracks.

My own motivation and prerequisites to serve as the Editor for ThCVS Reports are interest in scientific research, experience as a reviewer for different scientific journals, and to serve the German Society for Thoracic and Cardiovascular Surgery, being a member of its board of directors.
In my position as head of department and full professor of cardiovascular surgery in a more than 400 year-old, time-honoured university, I have more than enough activities and commitments. Therefore, I need the ongoing support of the experienced reviewers already working for the ThCVS.

Most of all, though, I need interesting, stimulating, and extraordinary reports from the international scientific community. Therefore, I would like to encourage you to keep on submitting papers to the ThCVS community. You will find the new special "Reports" submission site under:

http://mc.manuscriptcentral.com/tcsreports

Prof. Dr. Andreas Böning

Herz-, Kinderherz- und Gefäßchirurgie

Universitätsklinikum Giessen

Rudolf-Buchheim-Strasse 7

35392 Giessen

Germany

andreas.boening@chiru.med.uni-giessen.de
DOI http://dx.doi.org/ $10.1055 / \mathrm{s}-0032-1331470$. ISSN 2194-7635. 